\title{
Effects mediated by the $\alpha 7$ nicotinic acetylcholine receptor on cell proliferation and migration in rat adipose-derived stem cells
}

\author{
Marta Pernarella, ${ }^{1 *}$ Roberta Piovesana, ${ }^{1,2 *}$ Carlo Matera, ${ }^{3}$ Alessandro Faroni, ${ }^{2}$ Mario Fiore, ${ }^{4}$ Luciana Dini, ${ }^{1}$ \\ Adam J. Reid, ${ }^{2,5}$ Clelia Dallanoce, ${ }^{3}$ Ada Maria Tata ${ }^{1,6}$ \\ ${ }^{1}$ Department of Biology and Biotechnologies “Charles Darwin”, Sapienza University of Rome, Italy \\ ${ }^{2}$ Blond McIndoe Laboratories, Division of Cell Matrix Biology and Regenerative Medicine, University of Manchester, \\ UK \\ ${ }^{3}$ Department of Pharmaceutical Sciences, Medicinal Chemistry Section "Pietro Pratesi”, University of Milan, Italy \\ ${ }^{4}$ Institute of Molecular Biology and Pathology-CNR, Rome, Italy \\ ${ }^{5}$ Department of Plastic Surgery and Burns, Wythenshawe Hospital, University of Manchester, UK \\ ${ }^{6}$ Research Centre of Neurobiology “Daniel Bovet”, Sapienza University of Rome, Italy \\ *These authors equally contributed to this paper
}

\begin{abstract}
Adipose-derived stem cells (ASCs) are an attractive source for regenerative medicine as they can be easily isolated, rapidly expandable in culture and show excellent in vitro differentiation potential. Acetylcholine (ACh), one of the main neurotransmitters in central and peripheral nervous systems, plays key roles in the control of several physiological processes also in non-neural tissues. As demonstrated in our previous studies, ACh can contribute to the rat ASCs physiology, negatively modulating ASCs proliferation and migration via M2 muscarinic receptor $(\mathrm{mAChR})$ activation. In the present work we show that rat ASCs also express $\alpha 7$ nicotinic receptors (nAChRs). In particular, we have investigated the effects mediated by the selective activation of $\alpha 7$ nAChRs, which causes a reduction of ASC proliferation without affecting cell survival and morphology, and significantly promotes cell migration via upregulation of the CXCR4 expression. Interestingly, the activation of the $\alpha 7 \mathrm{nAChR}$ also upregulates the expression of $\mathrm{M} 2 \mathrm{mAChR}$ protein, indicating a cooperation between muscarinic and nicotinic receptors in the inhibition of ASC proliferation.
\end{abstract}

Key words: Acetylcholine; adipose-derived stem cells; alpha7 nicotinic receptor; proliferation; migration.

Correspondence: Prof. Ada Maria Tata, Department of Biology and Biotechnologies "Charles Darwin", Sapienza University of Rome, 00185 Rome, Italy. Tel. +39.06.49912822 - Fax: +39.06.39912317.

E-mail: adamaria.tata@uniroma1.it

Contributions: AMT, RP, MP, study concept and design; MP, RP, MF, data acquisition; AJR, RP, AF, dissection of adipose tissue and ASCs preparation; CM, CD, design and synthesis of ICH3; MP, RP, LD, AMT, data analysis and interpretation; MP, RP, AMT, manuscript drafting; AJR, CD, LD, MF, critical revision of this article. The final version of the revised manuscript was approved by all authors.

Conflict of interest: The authors declare no competing interests.

Availability of data and materials: The authors declare that all data supporting the findings of this study are available within the article.

Ethical Approval: All the experiments requiring animals were performed within the Biological Services Facilities (BSF) at the University of Manchester, in accordance with the UK Animals (Scientific Procedures) Act, 1986. Following terminal anaesthesia with $\mathrm{CO}_{2}$ and cervical dislocation (Schedule 1), tissues were harvested from the animals and processed as required for cell cultures preparation. 


\section{Introduction}

Mesenchymal stem cells (MSCs) are the most common cell population used in the biological research area and regenerative medicine, considering the lack of teratoma formation and ethical issue about their harvest. ${ }^{1-3}$ MSCs derive from the mesoderm layer that during embryogenesis originates different tissues; in the adult, they can be found in different perivascular niches, in bone marrow and adipose tissue. MSCs are an attractive tool for the clinical therapy given their easy in vitro expansion, their ability to differentiate into a variety of tissues producing trophic factors and cytokines and their high immunoregulatory capability. ${ }^{4-7}$ Bone marrow cellbased therapy is probably the most successful; the safe and controlled stem cell-based therapy has been widely proposed and is potentially useful in the regenerative medicine. ${ }^{8}$ In addition to the well-characterised MSC population from bone-marrow (BMMSCs), MSCs are found in other tissues as adipose tissue, peripheral blood, umbilical cord blood and foetal tissue. ${ }^{2}$ Among all the different MSCs, those derived from adipose tissue are among the most attractive in terms of therapeutic potential. ${ }^{9}$

Adipose tissue is composed of adipocytes, pre-adipocytes and a heterogeneous stromal cells population called stromal vascular fraction (SVF), that contains microvascular endothelial cells, blood cells, fibroblasts, smooth muscle and stem cells. ${ }^{9,10}$ A liposuction-extracted fat is rich in resident stem cells and over $50 \%$ of non-fat cells present stem cell markers. ${ }^{11}$ SVF population, composed of plastic-adhering cells, can be easily isolated through a mechanical and enzymatic digestion with collagenase, followed by centrifugation to remove the floating adipocytes. ${ }^{9}, 10$ As stated by the International Fat Applied Technology Society, the adopted name for the isolated, plastic-adherent, multipotent cell population is adipose-derived stem cells (ASCs). ${ }^{9,10}$ ASCs share some features with BM-MSCs, such as extensive self-renewal ability, multipotential differentiative capability (e.g., bone, fat, cartilage and muscle) and the lack of immunogenicity in autologous ASCs transplantation, allowing to bypass the use of immunosuppressive drugs. ${ }^{1,9,10,12-14}$ Although ASCs are similar to BM-MSCs, ASCs extraction provides a 100 -fold higher number of successfully isolated stem cells compared to the BM-MSC harvest. ${ }^{15}$ In addition, ASCs are easier to culture for longer periods and show faster growth rates, ${ }^{16}$ making this population a quite interesting tool for regenerative medicine. ${ }^{17}$ Moreover, in humans, ASCs can be easily isolated by conventional liposuction, a less invasive procedure compared with the painful bone marrow techniques. ${ }^{16,18}$

ASCs exhibit excellent regenerative qualities; for example, when exposed to a hypoxic environment, they express angiogenic factors, such as vascular endothelial growth factor-1 (VEGF), hepatocyte growth factor (HGF) and transforming growth factor beta (TGF- $\beta$ ), ${ }^{19}$ promoting new blood vessels sprouting. In peripheral nerve injury environment, ASCs are also able to secrete NGF and $\mathrm{BDNF}$, enhancing neuronal survival. ${ }^{20}$ Interestingly, in regenerative medicine, as described for BM-MSCs, ASCs can be differentiated into non-mesenchymal pathways under appropriate in vitro conditions, as Schwann-like phenotype, ${ }^{18,21}$ skeletal $^{10}$ and car$\operatorname{diac}^{9,10}$ myocytes and pancreatic-like cells, ${ }^{22}$ opening up new opportunities in cell replacement strategies ${ }^{18,23}$ and a debate within the regenerative medicine community on the impact of MSC transdifferentiation as opposed to other cell lineages usually derived from different germ layers. ${ }^{23}$ ASCs can work as a 'secretome', releasing growth factors in the extracellular matrix with a high impact on the various organs and systems. ${ }^{24}$ Additional anti-apoptotic, anti-oxidant and anti-inflammatory properties found for ASCs further highlight their potential in regenerative medicine..$^{25,26}$

The non-neuronal functions of the cholinergic system are largely documented, among them the involvement in the regulation of physiology of glial cells, ${ }^{27,28}$ immune cells ${ }^{29,30}$ and stem cells. ${ }^{31,32}$ MSCs express choline acetyltransferase (ChAT), acetylcholinesterase (AChE); moreover, nAChR subunits and metabotropic mAChR subtypes were detected in different mesenchymal cell types. ${ }^{32-34}$ As previously demonstrated, M2 mAChR activation negatively modulates ASC proliferation and migration. ${ }^{32}$ Although the expression of $\mathrm{nAChR}$, and in particular $\alpha 7$ receptor, has been reported in $\mathrm{ASCs},{ }^{34}$ the functional role of this subtype has been poorly investigated so far. The $\alpha 7 \mathrm{nAChR}$ is a homomeric channel expressed in several areas of the central (CNS) and peripheral (PNS) nervous systems ${ }^{35}$ as well as in other non-neuronal tissues. ${ }^{36-39}$ In the present study, we investigated the role of the $\alpha 7$ nicotinic receptors in rat ASC proliferation and migration and demonstrated that their selective activation promotes ASC migration and arrests cell proliferation.

\section{Materials and Methods}

\section{Statements for animal use}

All the experiments requiring animals were performed within the Biological Services Facilities (BSF) at the University of Manchester, in accordance with the UK Animals (Scientific Procedures) Act, 1986. Following terminal anaesthesia with $\mathrm{CO}_{2}$ and cervical dislocation (Schedule 1), tissues were harvested from the animals and processed as required to obtain the cell cultures.

\section{Adipose-derived stem cells harvesting and culture}

ASCs were harvested as previously reported; ${ }^{32,40}$ ASCs were isolated from adult male (3 months) Sprague-Dawley rats. Fat pads were dissected and minced using a sterile razor blade. After, tissue was enzymatically digested for $1 \mathrm{~h}$ at $37^{\circ} \mathrm{C}$ using $0.15 \%(\mathrm{w} / \mathrm{v})$ collagenase type I (Invitrogen, Manchester, UK). A $100 \mu \mathrm{m}$ filter was used to remove the undissociated tissue. The solution was centrifugated at $1200 \mathrm{rpm}$ for $10 \mathrm{~min}$ and the SVF obtained. The stromal cell pellet was plated in $75 \mathrm{~cm}^{2}$ cell culture flasks in stem cell growth medium consisting in minimum essential medium (MEM, Sigma-Aldrich, UK) supplemented with $10 \%(\mathrm{v} / \mathrm{v})$ foetal bovine serum (FBS, LabTech, Uckfield, UK), 1\% (v/v) Penicillin/ Streptomycin (Sigma-Aldrich, UK) and 1\% (v/v) Glutamine (Sigma-Aldrich, UK). The cultures were maintained at sub-confluent levels in a $37^{\circ} \mathrm{C}$ incubator with $5 \% \mathrm{CO}_{2}$ and passaged with trypsin/EDTA (Sigma-Aldrich, UK) when required.

\section{Cell treatments}

The compound 3-methoxy-1-oxa-2,7-diaza-7,10-ethanospirodec-2-ene sesquifumarate (ICH3) was used to selectively activate the $\alpha 7 \mathrm{nAChR} .{ }^{41-44} \mathrm{ICH} 3$ was used at the final concentration of 10 $\mu \mathrm{M}$. $\alpha$-Bungarotoxin (Tocris Bioscience, Bristol, UK), an $\alpha 7$ nicotinic receptor antagonist, was used at final concentration of 100 $\mathrm{nM}$ and it was added $2 \mathrm{~h}$ before $\mathrm{ICH} 3$ treatment. The M2 muscarinic receptor selective agonist arecaidine propargyl ester hydrobromide (APE, Sigma-Aldrich, Milan, Italy) was used at the final concentration of $100 \mu \mathrm{M} .^{32,45}$ Controls were obtained maintaining the cells in normal growth medium. Technical and experimental triplicates were performed for all experiments.

\section{RNA extraction and RT-PCR analysis}

Total RNA was extracted using Tri-Reagent (Sigma-Aldrich, UK). RNA concentration and purity were detected using the NanoDrop Lite Spectrophotometer (Thermo, Dreieich, Germany). One microgram of total RNA was reverse-transcribed into cDNA for $60 \mathrm{~min}$ at $37^{\circ} \mathrm{C}$ with $1 \mu \mathrm{g}$ of random Primers (Promega, Italy) and $200 \mathrm{U}$ of Moloney Murine Leukemia Virus (M-MLV) reverse 
transcriptase (Promega, Italy). The sequences of the primers used are reported in Table 1. Glyceraldehyde-3-phospate dehydrogenase $(\mathrm{GAPDH})$ was used as housekeeping gene. The densitometric analyses of the RT-PCR were performed by ImageJ imaging software (NIH, Bethesda, MD, USA).

\section{Western blot}

Cells were collected using Trypsin and centrifuged for $10 \mathrm{~min}$ at $1000 \mathrm{rpm}$ and the whole-cells lysates were resuspended and extracted in Lysis buffer (10 mM TrisEDTA, 0.5\% NP40, $150 \mathrm{mM}$ $\mathrm{NaCl}$ ) supplemented with protease inhibitors cocktail (SigmaAldrich, UK). Lysates were sonicated for 15 seconds, incubated for $30 \mathrm{~min}$ on ice and then centrifuged for $20 \mathrm{~min}$ at $14,000 \mathrm{rpm}$ at $4^{\circ} \mathrm{C}$. Protein concentration was determined using BCA Protein Assay Kit (Thermo Scientific, Waltham, MA, USA), according to the manufacturer's protocol. Sample buffer $(4 \times)$ was added to the protein sample, heated for $5 \mathrm{~min}$ at $100^{\circ} \mathrm{C}$, loaded onto a $12 \%$ SDS polyacrylamide gel and run at $100 \mathrm{~V}$ using running buffer $(0.25 \mathrm{M}$ Tris, 2.4 M Glycine, 0.035 M SDS). SDS-PAGE gels were transferred onto PVDF membranes (Polyvinylidene fluoride, Merck Millipore, Darmstadt, Germany) at $200 \mathrm{~mA}$ in transfer buffer (20 $\mathrm{mM}$ Tris; $150 \mathrm{mM}$ glycine, $10 \%[\mathrm{v} / \mathrm{v}]$ methanol) for $2 \mathrm{~h}$ at $4{ }^{\circ} \mathrm{C}$. Membranes were blocked for $30 \mathrm{~min}$ in $5 \%$ of non-fat dry milk (Sigma-Aldrich, Italy) in Tris-buffer saline (TBS) containing $0.1 \%$ Tween-20, and then incubated, at $4{ }^{\circ} \mathrm{C}$ overnight, with the antibodies previously diluted in the blocking solution. Primary antibodies used were: rabbit anti- $\alpha 7$ antibody (dilution 1:500, Bioss, MA, USA, bs-1049R), mouse anti-M2 antibody (dilution 1:800, NovusBio, CO, USA, NB120-2805), rabbit anti-CXCR4 (dilution 1:300, NovusBio, CO, USA, AB_10001320), rabbit anti-Cyclin D1 (1:100, Santa Cruz Biotechnology, CA, USA), mouse anti- $\beta$ actin (1:2000; Immunological Sciences, Rome, Italy; AB-24008). After overnight incubation, membranes were washed three times with PBS- $0.1 \%$ Tween-20 buffer and then incubated for $1 \mathrm{~h}$ at room temperature (RT) with secondary antibody: anti-rabbit horseradish peroxidase (1:10000, Promega, Italy) or anti-mouse horseradish peroxidase (1:10000, Immunological Sciences). Membranes were exposed to ECL chemiluminescence reagent (Immunological Science) for signal detection. The bands were detected by exposition to Chemidoc (Molecular Imager ChemiDoc XRS + System with Image Lab Software, Bio-Rad, CA, USA). Band intensities were quantified as optical density using ImageJ imaging software (NIH, Bethesda, MD, USA).

\section{Immunocytochemistry}

ASCs were seeded in completed medium at the density of $4 \times 10^{3}$ on coverslips arranged in 24 well-plates. The following day, cells were treated as required by experimental plan. Then ASCs were washed three times with PBS and fixed with $4 \%$ paraformaldehyde in PBS for 20 min at RT. After three washes in PBS, cells were pre-incubated in PBS solution containing $0,1 \%$ Triton $\mathrm{X}-100,1 \%$ bovine albumin serum (BSA) and 10\% normal goat serum (NGS) for $45 \mathrm{~min}$ at RT. Cells were then incubated with a polyclonal rabbit anti- $\alpha 7$ antibody (dilution 1:100; Bioss, bs1049R) at $4{ }^{\circ} \mathrm{C}$ overnight. The next day, after three washes in PBS, cells were incubated with Alexa-488-conjugated goat anti-rabbit (IgG diluted 1:200 in PBS $+0.1 \%$ Triton X-100 $+1 \%$ NGS; Immunological Sciences) for $2 \mathrm{~h}$ at RT. After three washes in PBS, the cells were mounted with Anti-Fade Mounting Medium with 4',6-diamidino-2-phenylindole (DAPI, Immunological Science).

The images were acquired with a Zeiss fluorescence microscope, using a 20x objective through the Axion Vision program (Zeiss, Oberkochen, Germany).

\section{Proliferation assay-MTT assay}

ASCs were seeded on 24-well plate at the density of $25 \times 10^{3}$ cells/well. After $24 \mathrm{~h}$ of plating, cells were treated with $10 \mu \mathrm{M}$ ICH3 and incubated at different times, up to $96 \mathrm{~h}$. Cell growth was assessed by a colorimetric assay based on 3-(4,5-dimethylthiazol2-y1)-2,5-diphenyltetrazolium bromide (MTT, Sigma-Aldrich, St. Louis, MO, USA) metabolization. For each well, the OD at $570 \mathrm{~nm}$ was measured by GloMax Multi Detection System (Promega, Madison, WI, USA). Cells maintained in different experimental condition were photographed by a phase contrast microscope (Axiovert, Zeiss).

\section{Rescue of cell proliferation}

To assess whether the ICH3-induced reduction of cell proliferation was reversible, a recovery analysis was set up. Cells were seeded in $60 \mathrm{~mm}$ diameter plates at a cell density of $60 \times 10^{3}$ cells/dish. The day after seeding, the cells were treated with $10 \mu \mathrm{M}$ ICH3 and maintained in culture for $48 \mathrm{~h}$. After two days, complete medium containing ICH3 was removed from the culture medium; the cells were washed once with sterile PBS, and fresh complete media added for $48 \mathrm{~h}$. Then the cells were collected by trypsinization and counted.

\section{Flow cytometry assay}

The cells were plated on $90 \mathrm{~mm}$ diameter dishes at a density of $200 \times 10^{3}$ cells/dish. The day after plating, cells were treated with $10 \mu \mathrm{M} \mathrm{ICH} 3$ for $48 \mathrm{~h}$. At the end of the treatment, cells were incubated for 90 min with $45 \mu \mathrm{M}$ bromodeoxyuridine (final concentration) (BrdU, Sigma-Aldrich, UK), collected by trypsinization, centrifuged for 10 minutes at $1000 \mathrm{rpm}$ and then fixed in methanol/PBS 1:1 (v/v). To identify cells in S phase, DNA content and $\mathrm{BrdU}$ incorporation were determined in simultaneous analysis by staining with propidium iodide (PI) and anti-BrdU respectively. Partial DNA denaturation was performed by incubating the cells in $3 \mathrm{~N} \mathrm{HCl}$ for $45 \mathrm{~min}$, followed by neutralization with $0.1 \mathrm{M}$ sodium tetraborate. Samples were then incubated with monoclonal mouse anti-BrdU (1:50 v/v; Dako, Santa Clara, CA, USA; RRID: $\mathrm{AB}$ 10013660) for $60 \mathrm{~min}$ at RT, washed twice with $0.5 \%$ Tween20 in PBS and incubated for 45 min with anti-mouse Alexa 488conjugated (1:600) (Promega Italia, Milan, Italy). After washing samples with PBS plus $0.5 \%$ Tween-20, cells were stained with 10 $\mu \mathrm{g} / \mathrm{ml}$ PI for $15 \mathrm{~min}$ at RT. Flow cytometry analysis was performed with a flow cytometer Coulter Epics XL with $488 \mathrm{~nm}$ wavelength excitation and $10^{4}$ events were collected for each sample. Bi-parametric (DNA content versus BrdU content) analyses were performed using WinMDI 2.9 software.

Table 1. Primer sequences used in semiquantitative RT-PCR analysis

\begin{tabular}{lrr} 
Gene & \multicolumn{1}{c}{ Forward } & Reverse \\
GAPDH & 5'-TGGCATTGTGGAAGGGCTCATGAC-3' & 5'-ATGCCAGTGAGCTTCCCGTTCAGC-3' \\
$\alpha 7$ & 5'-AACCATGCGCCGTAGGACA-3' & 5'-CTCAGCCACAAGCAGCATGAA-3' \\
\hline CXCR4 & 5'-GCTCCAATGATTCGACGTCA-3' & 5'-CGAAGTGGAAACTGTTGTTTTCAT-3' \\
\hline CyclinD1 & 5' GCCATGGCTGACTGGTACTT 3' & 5' GATGAAGGCCAGGATGAGAA 3' \\
\hline
\end{tabular}




\section{Wound healing}

Cell migration was evaluated through wound healing assay; $300 \times 10^{3}$ cells were plated in a $60 \mathrm{~mm}$ diameter plate. Cells were maintained in complete medium until semi-confluence was reached. The experimental conditions, each of which made in triplicate, were control, $10 \mu \mathrm{M}$ ICH3 and $10 \mu \mathrm{M}$ ICH3 plus $100 \mathrm{nM}$ $\alpha \mathrm{BTX}$. The day of wound healing test, cells were pre-treated with the antagonist $(\alpha \mathrm{BTX})$ for $2 \mathrm{~h}$ before the agonist and then they were also pre-treated with ICH3 for $1 \mathrm{~h}$ before scratch, as required in the experimental plan. After pre-treatment, wound was generated with p200 tip. The cells were photographed at time $0 \mathrm{~h}$ and after $6 \mathrm{~h}$ from the scratch using a 20x magnification objective. The space between two fronts at time $0(\mathrm{t} 0)$ and $6 \mathrm{~h}(\mathrm{t} 6)$ was measured. The two values were subtracted, obtaining the covered space by the cells in the experimental time chosen. After $6 \mathrm{~h}$, cells were fixed with $4 \%$ paraformaldehyde (PFA) in PBS (Sigma-Aldrich, UK), permealized for 15 min with $0.2 \%(\mathrm{v} / \mathrm{v})$ Triton-X100 in PBS (Sigma-Aldrich, UK) and stained for $20 \mathrm{~min}$ at RT with Alexa 488conjugated phalloidin (1:40, Life Technologies, UK) diluted in PBS $+1 \%(w / v)$ BSA. Images were obtained using a fluorescence microscope (Zeiss) and processed with ImageJ imaging software (NIH, Bethesda, MD, USA).

\section{Statistical analysis}

Data analyses were performed with GraphPad Prism 6.0 (GraphPad Software Inc, La Jolla, CA). Data were presented as the mean \pm SEM. Student's $t$-test was used for the analyses of RT-PCR and western blot whereas one-way ANOVA test followed by Bonferroni's post-test was used to evaluate statistical significance within the different samples in proliferation analyses, Cyclin D1 Western blot, FACS analysis and migration assays. A value of $\mathrm{p}<0.05$ was considered statistically significant: $\mathrm{p}<0.05(*), \mathrm{p}<0.01$ $(* *), \mathrm{p}<0.001(* * *)$ and $\mathrm{p}<0.0001(* * * *)$.

\section{Results}

\section{Characterization of the $\alpha 7$ nicotinic receptor in ASCs}

ASCs are positive for different markers including CD29, CD44, and CD90. Previously, the characterization of stemness markers to confirm the stemness nature of ASCs cultures was performed. ${ }^{32}$ The $\alpha 7 \mathrm{nAChR}$ expression was analysed in ASCs by RTPCR and Western blot analysis, which allowed to detect expression of both $\alpha 7$ transcript (Figure 1A) and protein, respectively (Figure 1B). We evaluated whether the activation of the $\alpha 7$ subtype could
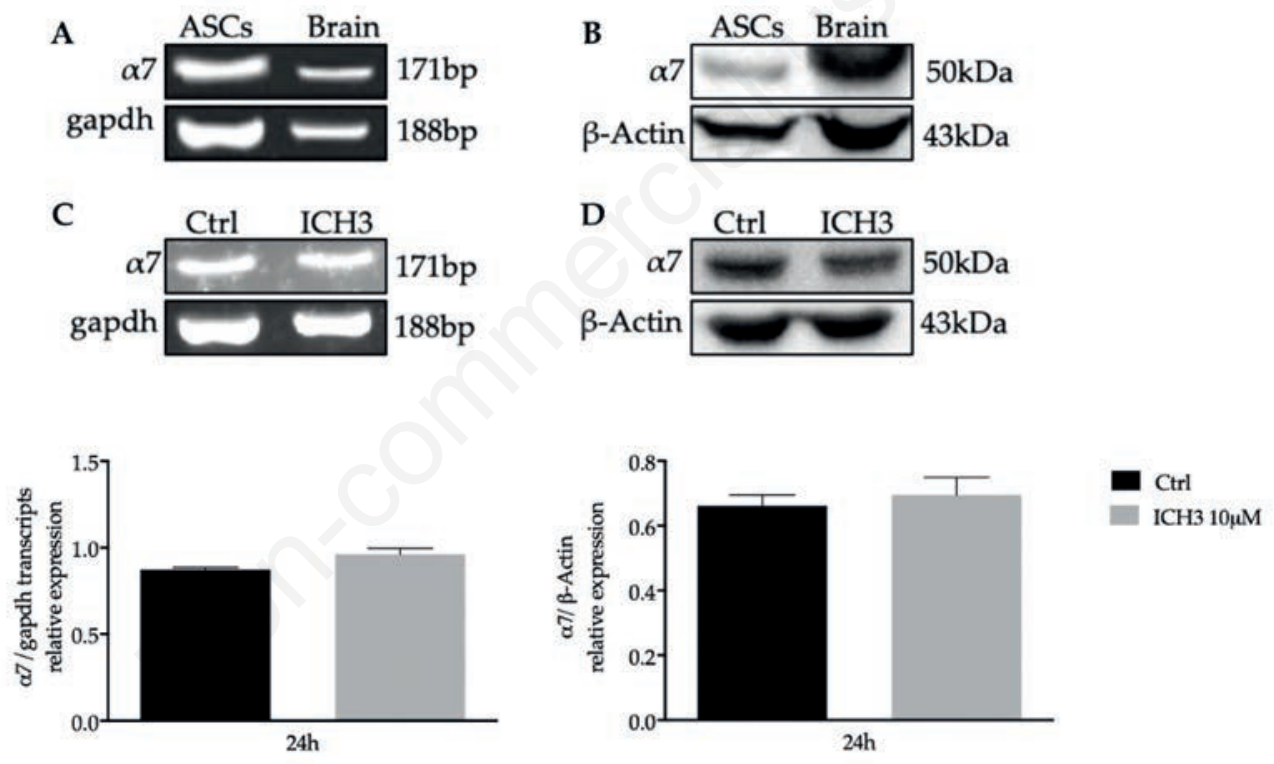

E
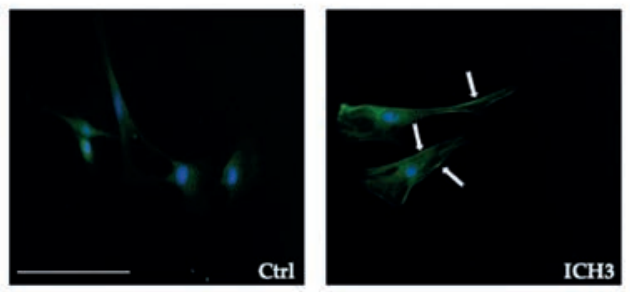

Figure 1. $\alpha 7$ nicotinic receptor expression. ASCs express $\alpha 7$ receptor as transcript (RT-PCR) (A) and protein (Western blot) (B); rat brain was used as positive control. RT-PCR (C) and Western blot (D) analysis of the $\alpha 7$ receptor transcript in the absence or presence of $10 \mu \mathrm{M} \mathrm{ICH} 3$; the cells treated for $24 \mathrm{~h}$ do not show any particular variation of transcript and protein levels. GAPDH was used as housekeeping gene, whereas $\beta$-actin as reference protein; data are represented as mean \pm SEM of three independent experiments. E) Immunocytochemistry analysis for $\alpha 7$ in ASCs following treatment with ICH3; the arrows indicate the receptor localization at cell membrane level; scale bar: $50 \mu \mathrm{m}$. 
induce an autocrine regulation of its expression in ASCs. To this aim, ASCs were treated with the selective agonist 3-methoxy-1oxa-2,7-diaza-7,10-ethanospiro-dec-2-ene sesquifumarate $(\mathrm{ICH} 3)^{41-44}$ at the final concentration of $10 \mu \mathrm{M}$. Treatment with the agonist did not induce a significant modulation of the expression of the $\alpha 7$ receptor both at the transcriptional and protein level, as demonstrated by the RT-PCR and Western blot analysis, respectively (Figure $1 \mathrm{C}, \mathrm{D})$. The expression of this receptor was further analysed through immunocytochemistry. Although this approach did not allow a quantitative analysis, the level of receptor expression resulted unchanged, while receptor distribution appeared different. Indeed, in the untreated cells the staining was mainly cytoplasmic, whereas a marked staining at plasma membrane was observed after treatment with ICH3 (Figure 1E).

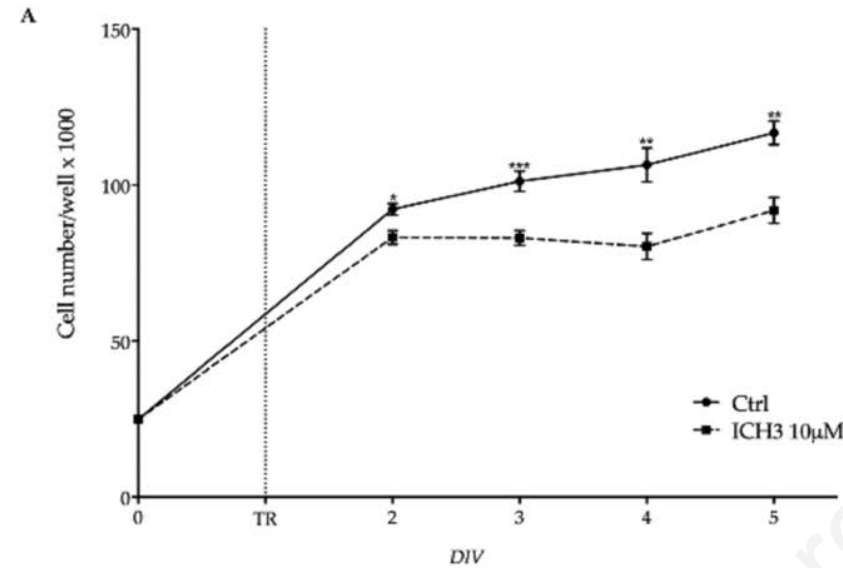

C

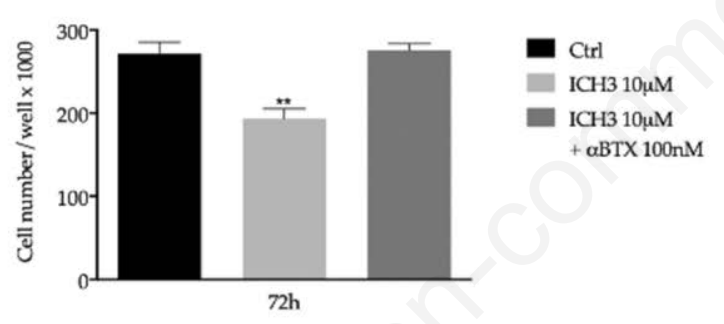

D

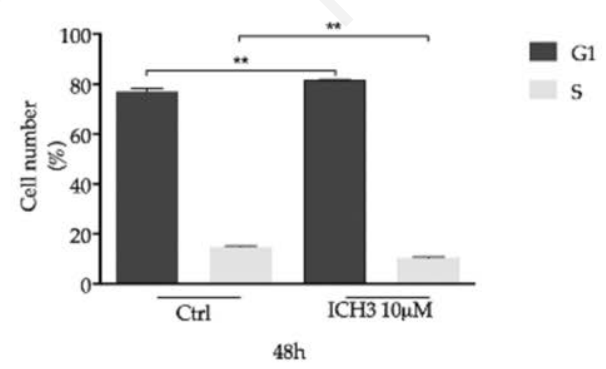

\section{Activation of the $\alpha 7$ receptor inhibits ASC proliferation}

Using MTT analysis, we found that the activation of the $\alpha 7$ nAChR by the selective agonist ICH3 negatively regulated ASC proliferation. ASCs treated with $10 \mu \mathrm{M}$ ICH3 up to $96 \mathrm{~h}$ showed a reduction of cell growth, which was already significant after $24 \mathrm{~h}$ of treatment (Figure 2A). As shown in Figure 2B, the phase-contrast images indicated that, in presence of $\mathrm{ICH} 3$, the number of ASCs was significantly reduced. No evidence of dead floating cells was observed. To confirm that this effect is mediated by the selective activation of the $\alpha 7$ receptor, cells were pre-treated with the antagonist $\alpha$-Bungarotoxin $(100 \mathrm{nM})$ and then with ICH3. The number of cells counted after this treatment indicated that $\alpha \mathrm{BTX}$ was able to counteract the effects of ICH3 (Figure 2C).

B

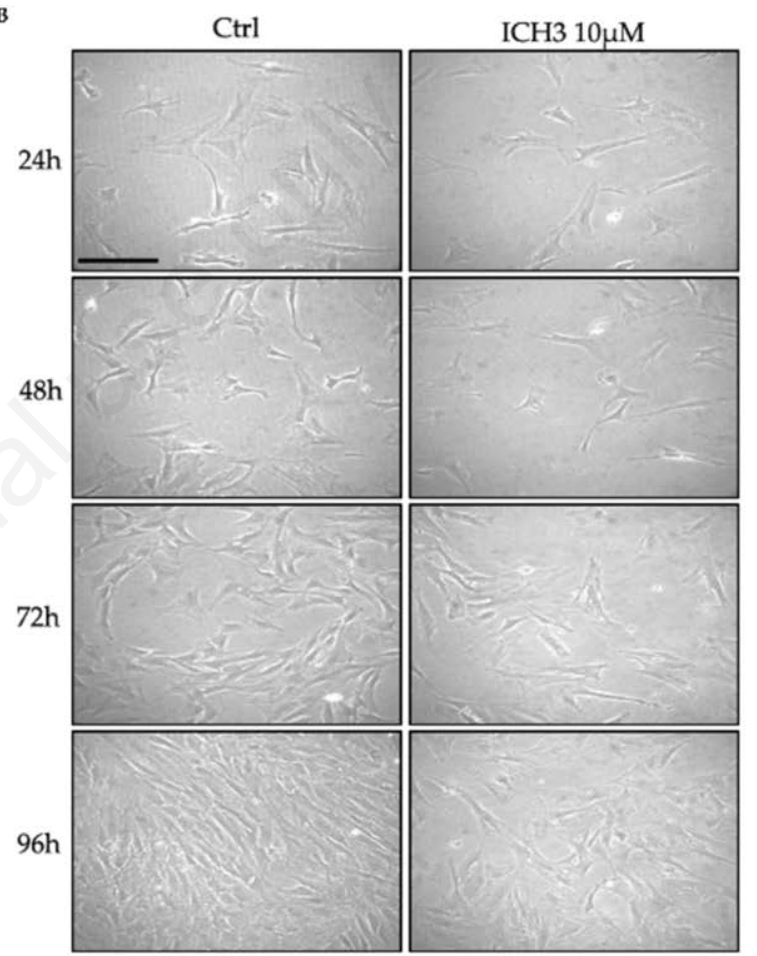

E

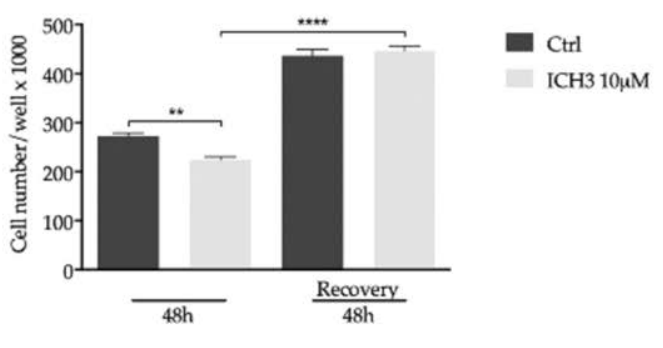

Figure 2. The activation of $\alpha 7$ receptor causes a reversible decrease of cell proliferation. A) Analysis of cell growth by MTT assay showed a decrease of cell growth in ASC cultures treated with $10 \mu \mathrm{M} I C H 3\left({ }^{*} \mathrm{P}<0.05 ;{ }^{* *} \mathrm{P}<0.01 ;{ }^{* * *} \mathrm{P}<0.001\right)(\mathrm{DIV}=$ day in vitro). B) Images show a decreased number of cells/field. The absence of floating cells is observable; scale bar: $100 \mu \mathrm{m}$. C) Cell counts performed after $72 \mathrm{~h}$ of treatment with $10 \mu \mathrm{M}$ ICH3 in presence or absence of $100 \mathrm{nM} \alpha \mathrm{BTX}$, showed that the antagonist was able to counteract the ICH3-mediated reduced cell number $(* * \mathrm{P}<0.01)$. D) Percentage of cells in G1 and S phases obtained by FACS analysis; after ICH3 treatment a significant reduction of cells in $S$ phase and an increase in G1 phase were observed $\left({ }^{* *} p<0.01\right)$. E) Recovery analysis assessed by cell count; following $10 \mu \mathrm{M}$ ICH3 treatment for $48 \mathrm{~h}$, after agonist withdrawal from the culture medium the cells were maintained in complete medium for additional $48 \mathrm{~h}$. The data showed a full recovery of the cell proliferation rate $\left({ }^{* *} \mathrm{p}<0.01 ; \mathrm{Ctrl} v s \mathrm{ICH} 3\right.$; ${ }^{* * * *} \mathrm{p}<$ 0.0001 ; ICH3 vs ICH3 recovery). The results are the mean \pm SEM of at least three independent experiments conducted in triplicate. 
To confirm the hypothesis regarding the $\alpha 7$ receptor's ability to control cell proliferation, we performed a FACS analysis in which ASCs were maintained in the presence or absence of $10 \mu \mathrm{M} \mathrm{ICH} 3$ for $48 \mathrm{~h}$. As indicated in the Figure 2D, ASCs following treatment with $\mathrm{ICH} 3$ showed a significant reduction of the percentage of cells in $\mathrm{S}$ phase compared to the control condition. However, measuring the time of replication, we obtained a significant reduction of the cell proliferation rate with a replication time of $120 \mathrm{~h}$ (after 2 days in vitro) and $300 \mathrm{~h}$ (after 3 days in vitro; data not shown).

By considering the negative effects of $\alpha 7 \mathrm{nAChR}$ stimulation on cell proliferation, a recovery assay was performed to understand if ASCs were able to restore their proliferative rate after nicotinic agonist withdrawal. Cells were thus plated and treated for $48 \mathrm{~h}$ with $10 \mu \mathrm{M}$ ICH3. Then, the agonist was removed, and a fresh medium was added. The cell number was assessed by cell count 48 $\mathrm{h}$ after the $\alpha 7$ agonist withdrawal. ASCs were able to rescue the normal proliferative rate condition, indicating that the treatment with the selective agonist caused a reduction of proliferative rate that can be restored after the agonist withdrawal (Figure 2E). To better characterize the decreased cell proliferation after $\alpha 7$ nAChRs activation, we performed the analysis of Cyclin D1 expression. The analysis of the transcript of Cyclin D1 by RT-PCR showed that the treatment with ICH3 significantly reduced its expression level (Figure 3A), whereas Western blot analysis showed a meaningful increase of protein levels following $\alpha 7$ nAChR activation. The increased ICH3-induced Cyclin D1 protein expression was counteracted by the $\alpha 7$ antagonist $\alpha$ BTX (Figure 3B).

\section{$\alpha 7$ nicotinic receptors modulate ASC migration}

To evaluate the $\alpha 7$ agonist effect on cell migration, the wound healing technique was used (Figure $4 \mathrm{~A}$ ). When required, $\alpha \mathrm{BTX}$ was added to the culture medium $2 \mathrm{~h}$ before ICH3 treatment. Six hours after scratch, the distance between the two fronts was measured in the treated and untreated cells, as described in Materials and Methods. The graph shows the distance travelled by the cells in the chosen experimental time and indicates that the selective $\alpha 7$ receptor activation significantly increased cell migration (Figure $4 \mathrm{~B})$. The $\alpha 7$ antagonist $\alpha \mathrm{BTX}$ counteracted the enhanced ICH3induced cell migration.

Being the CXCR4 receptor a protein involved in the chemotactic activities, we investigated whether the increased migration observed could be related to a modulated expression of this chemokine receptor. The analysis of the CXCR4 protein expression showed that the $\alpha 7$ agonist treatment caused a significant increase of the levels of CXCR4 receptor protein, whereas we did not observe any modulation at transcriptional levels (Figure 4 C,D).

\section{Cross-interaction between $\alpha 7$ nicotinic and M2 mus- carinic receptors}

Given the results obtained in a previous study about the M2 receptor meaningful upregulation after exposure to the M2 receptor agonist, $\mathrm{APE},{ }^{32}$ we examined the putative modulation of the $\alpha 7$ nAChR and M2 mAChR expression upon treatment with M2 receptor agonist and ICH3. Figure 5A shows the lack of a significant modulation of the $\alpha 7$ receptor protein expression after treatment with the M2 receptor agonist APE. Instead, although the treatment with $\mathrm{ICH} 3$ did not affect the transcript level of the M2 receptor (Figure 5C), a significant increase of the $\mathrm{M} 2$ receptor protein level was detected (Figure 5D).

\section{Discussion}

In the present work, we confirm the cholinoceptivity of rat ASCs. They express $\alpha 7 \mathrm{nAChRs}$ subtype and its selective activation causes a reversible reduction of cell proliferation without affecting neither cell survival nor morphology and significantly promoting cell migration.

Adipose tissue is a complex tissue formed by different types of cells, including stem cells. ${ }^{13}$ It is an abundant source of stem cells
A
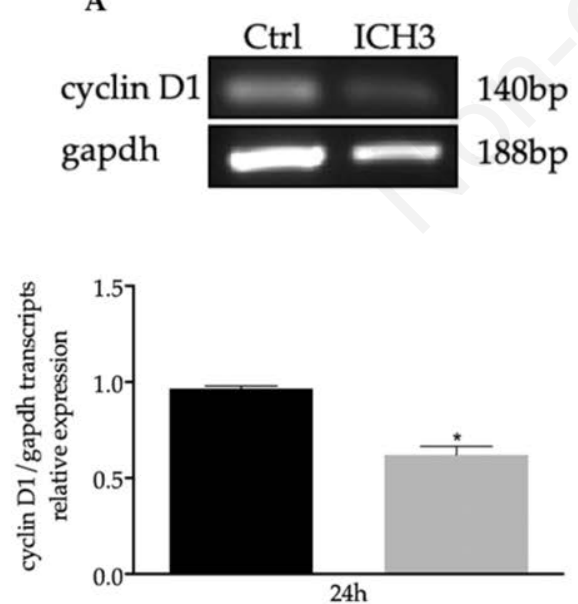

B
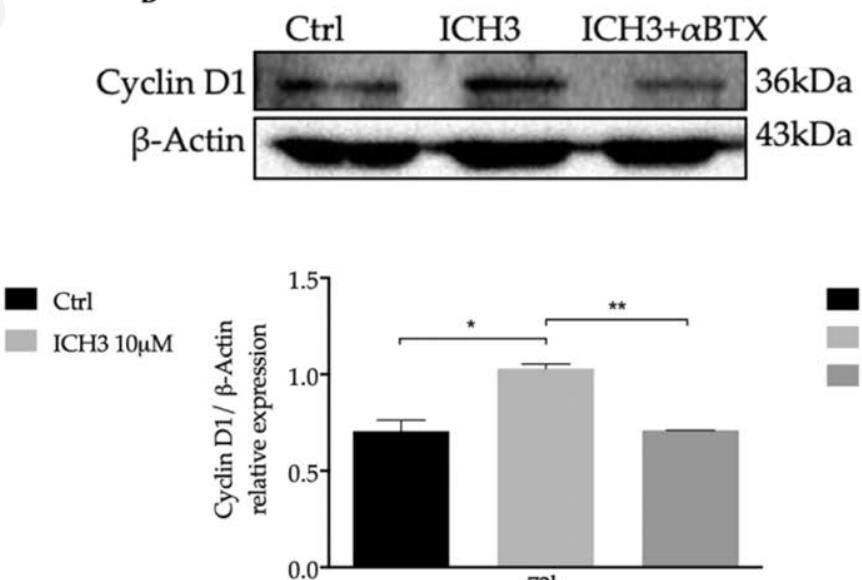

Ctrl

ICH3 $10 \mu \mathrm{M}$

- ICH3 $10 \mu \mathrm{M}$ $+\alpha \mathrm{BTX} 100 \mathrm{nM}$

Figure 3. The selective activation of $\alpha 7$ receptor modulates the expression of Cyclin D1. A) RT-PCR expression analysis of Cyclin D1 in ASCs in the presence or absence of $10 \mu \mathrm{M}$ ICH3; treatment with ICH3 caused a significant reduction in the transcript level of Cyclin D1; the graph below indicates the densitometric analysis of the bands obtained from three independent experiments, normalized with the housekeeping gene, GAPDH $\left({ }^{*} \mathrm{p}<0.05\right)$. B) Western blot and densitometric analysis of the levels of Cyclin D1 protein in untreated cells (Ctrl), and cells treated with $10 \mu \mathrm{M}$ ICH3 or $10 \mu \mathrm{M}$ ICH3 + $100 \mathrm{nM} \alpha$-BTX $(72 \mathrm{~h})$; $\alpha$-BTX was added to the culture medium $2 \mathrm{~h}$ before ICH3 treatment; the selective activation of the $\alpha 7$ receptor induced a significant increase of the expression of Cyclin D1, whereas the presence of the $\alpha 7$ antagonist, $\alpha$ BTX, counteracted the effects of $\mathrm{ICH} 3$, resulting in an expression of Cyclin D1 comparable to that of control; $\beta$-Actin was used as the reference protein $\left({ }^{*} \mathrm{p}<0.05 ;{ }^{* *} \mathrm{p}<0.01\right)$. 
with a great trans-differentiation capability and an easier withdrawal, and these properties make this population very attractive for regenerative medicine. ${ }^{12,15,18,23,46}$ Moreover, the role of ASCs as a secretome relevantly impacts on the homeostasis of different organs and systems. ${ }^{24}$ Since all these features are regulated by different modulators and growth factors, ${ }^{33}$ a full understanding of the ASC biology is far from being achieved.

In addition to its function as a neurotransmitter, ACh plays different roles in several non-neuronal tissues. ${ }^{38,47-52}$ In a previous paper, we highlighted that ASCs respond to ACh and that the selective stimulation of M2 mAChRs negatively regulates ASC proliferation and migration, preserving ASCs in a quiescent state until the maintenance of $\mathrm{M} 2$ receptor activation. ${ }^{32}$ According with the results from other authors, MSCs, and ASCs, express other cholin- ergic receptors, such as different nicotinic subtypes, ${ }^{33,34}$ and they are able to synthesize ACh, suggesting the existence of an autocrine and/or paracrine cholinergic circuit. ${ }^{33,53}$ In this paper, we clearly show that rat ASCs express the $\alpha 7 \mathrm{nAChR}$ both as transcript and protein. Our analysis on ASCs took advantage of the application of ICH3, which was characterized as a selective orthosteric agonist of the $\alpha 7$ receptor subtype. ${ }^{41-44}$ Although the selective activation with ICH3 did not modify the level of $\alpha 7$ receptor neither as transcript nor as protein, however a different localization, from cytoplasm to the cell membrane, was observed after exposure to $\mathrm{ICH} 3$ indicating that the selective stimulation contributes to export the $\alpha 7$ receptor on the plasma-membrane. Based on our previous data, which indicated a substantial upregulation of the M2 subtype after exposure to an M2 agonist ${ }^{32}$, the analysis of $\alpha 7$

A
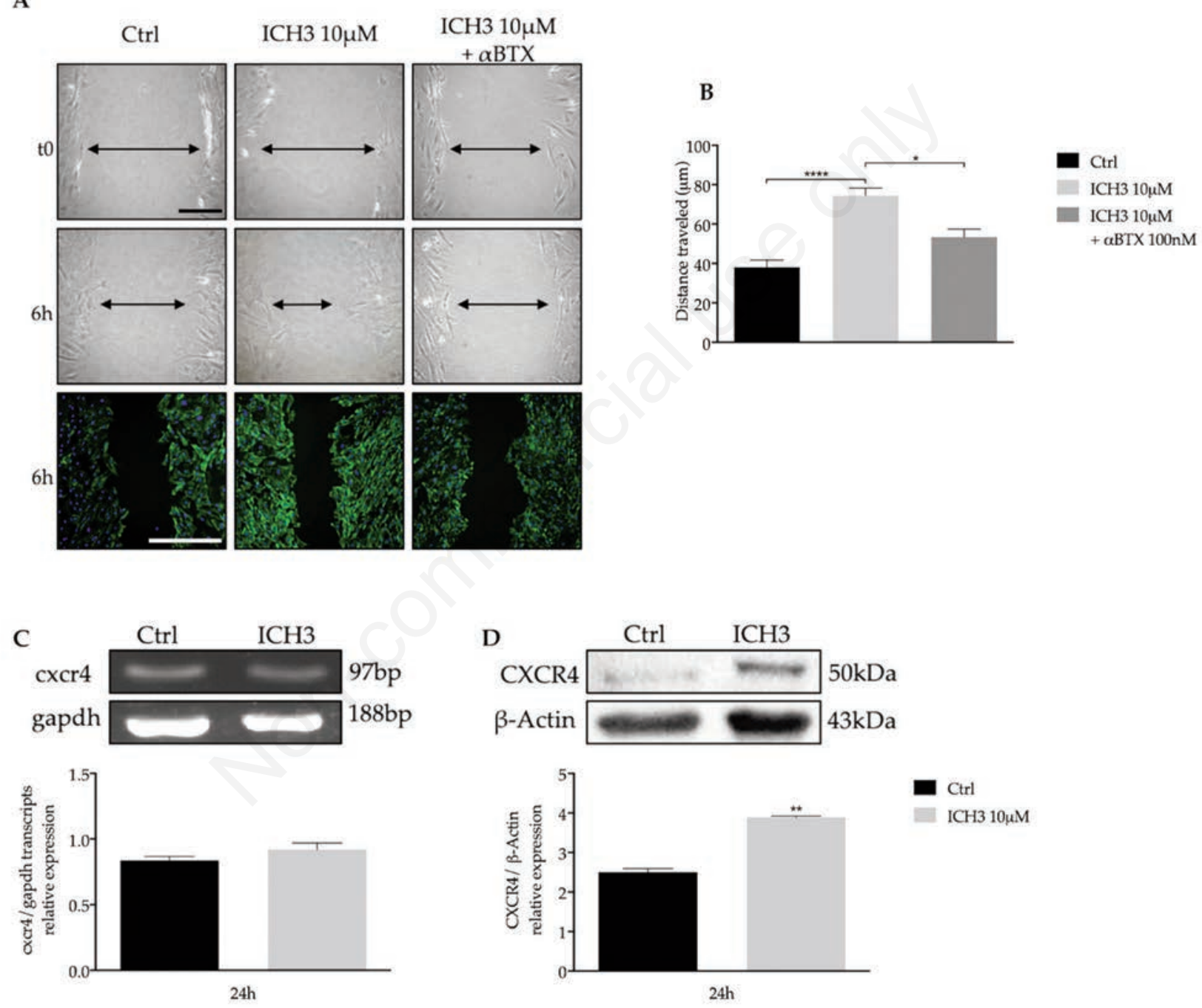

Figure 4. Analysis of ASC migration. A) The analysis of cell migration was performed by the wound healing assay; the images obtained

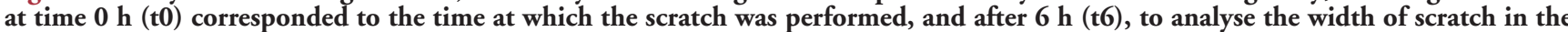
control and ICH3-treated cells; the distance of the gap between two fronts was measured at the two different time points; scale bar: 100 $\mu \mathrm{m}$; the bottom panel shows the cells stained with phalloidin; scale bar: $100 \mu \mathrm{m}$. B) The graph shows the distance travelled by the cells (t0-t6) in the different experimental conditions; ICH3 treatment significantly increased cell migration; the data obtained are the mean \pm SEM at least three independent experiments carried out in triplicate $\left({ }^{* * * *} \mathrm{p}<0.0001 \mathrm{Ctrl} v s \mathrm{ICH} 3 ;{ }^{*} \mathrm{P}<0.05 \mathrm{ICH} 3\right.$ vs ICH3+ $\left.\alpha \mathrm{BTX}\right)$. C) RT-PCR analysis of the CXCR4 transcript after $10 \mu \mathrm{M} \mathrm{ICH} 3$ treatment; the graph indicates the densitometric analysis of the bands normalized against GAPDH, used as housekeeping gene; transcript level remained unchanged after ICH3 treatment. D) Western blot and densitometric analysis of CXCR4 protein in untreated (Ctrl) and treated (10 $\mu \mathrm{M} \mathrm{ICH3)}$ cells for $24 \mathrm{~h}$; $\beta$-actin was used as reference protein $\left({ }^{* *} \mathrm{p}<0.01\right)$; although ICH3 treatment did not change the expression of CXCR4 transcript, it induced a significant upregulation of the protein level; the results are the mean \pm SEM of three independent experiments. 
expression did not show any significant modulation after APE treatment. On the other hand, an upregulation of the M2 receptor protein was evidenced after $\alpha 7$ receptor stimulation, suggesting a cross-modulation in ASCs of the two different cholinergic receptor types. The nicotinic stimulation decreased cell growth up to four days after treatment without affecting cell survival, with a reduction of the percentage of cells in $\mathrm{S}$ phase after $48 \mathrm{~h}$ of treatment; this event was counteracted by the selective $\alpha 7$ nicotinic antagonist, $\alpha$ BTX. Since we did not observe floating cells, this suggest the absence of dead cells, demonstrating that the treatment used does not affect cell survival. Taking the advantage by FACS analysis data, we calculated the duplication time and found a significant increase of the time used for replication after $72 \mathrm{~h}$ of treatment, suggesting that the $\alpha 7$ receptor stimulation causes a decrease of the ASC proliferation rate rather than an arrest of their cell cycle. This result is also confirmed by the ability of the ASCs to rescue cell proliferation; in fact the reduction of cell growth was reversible and cells recovered their proliferative rate after withdrawal of the $\alpha 7$ agonist, similarly to what observed after M2 receptor stimulation. ${ }^{32}$ The $\alpha 7$-mediated inhibition of cell proliferation detected by MTT and FACS analysis was followed by a significant downregulation of the Cyclin D1 transcript level and, in contrast, with a significant upregulation of the Cyclin D1 protein level. The two opposite effects could be explained by a temporary block of the cells in S phase; in this condition, the increased level of the Cyclin D1 protein may be a consequence of cell accumulation and this may directly influence also the expression of the Cyclin D1 transcript. Interestingly, $\alpha$ BTX counteracted the modulated expression of the Cyclin D1 protein, thus validating the selectivity of the agonist and the specific involvement of the $\alpha 7$ receptor subtype. ACh, through $\mathrm{M} 2$ receptors, is also able to decrease cell growth $^{32}$ and adult stem cells and other cells in the stem niche synthetize ACh, as indicated by the expression of the related biosynthetic enzyme ChAT. Therefore, we may hypothesize that ACh, by activating receptor-dependent cholinergic pathways, is able to inhibit ASC proliferation, preserving their quiescent status and plasticity.

Cell migration is a fundamental event for stem cells, which allows their movement from the stem cell niches to reach the damaged tissue to maintain the tissue homeostasis and to modulate inflammatory and regenerative processes. Cell migration is depending on CXCL12/SDF-1-CXCR4/CXCR7 pathway. ${ }^{54}$ In our experiments, we evidence that the $\alpha 7$ agonist ICH3 efficiently promotes ASC migration, with a relevant upregulation of the CXCR4 protein level. Even these positive effects mediated by the $\alpha 7$ receptor were counteracted by the selective antagonist $\alpha \mathrm{BTX}$. Thus, our data suggest that ACh could act as one of the factors modulating ASC migration, which is promoted or arrested via activation of $\alpha 7$

A
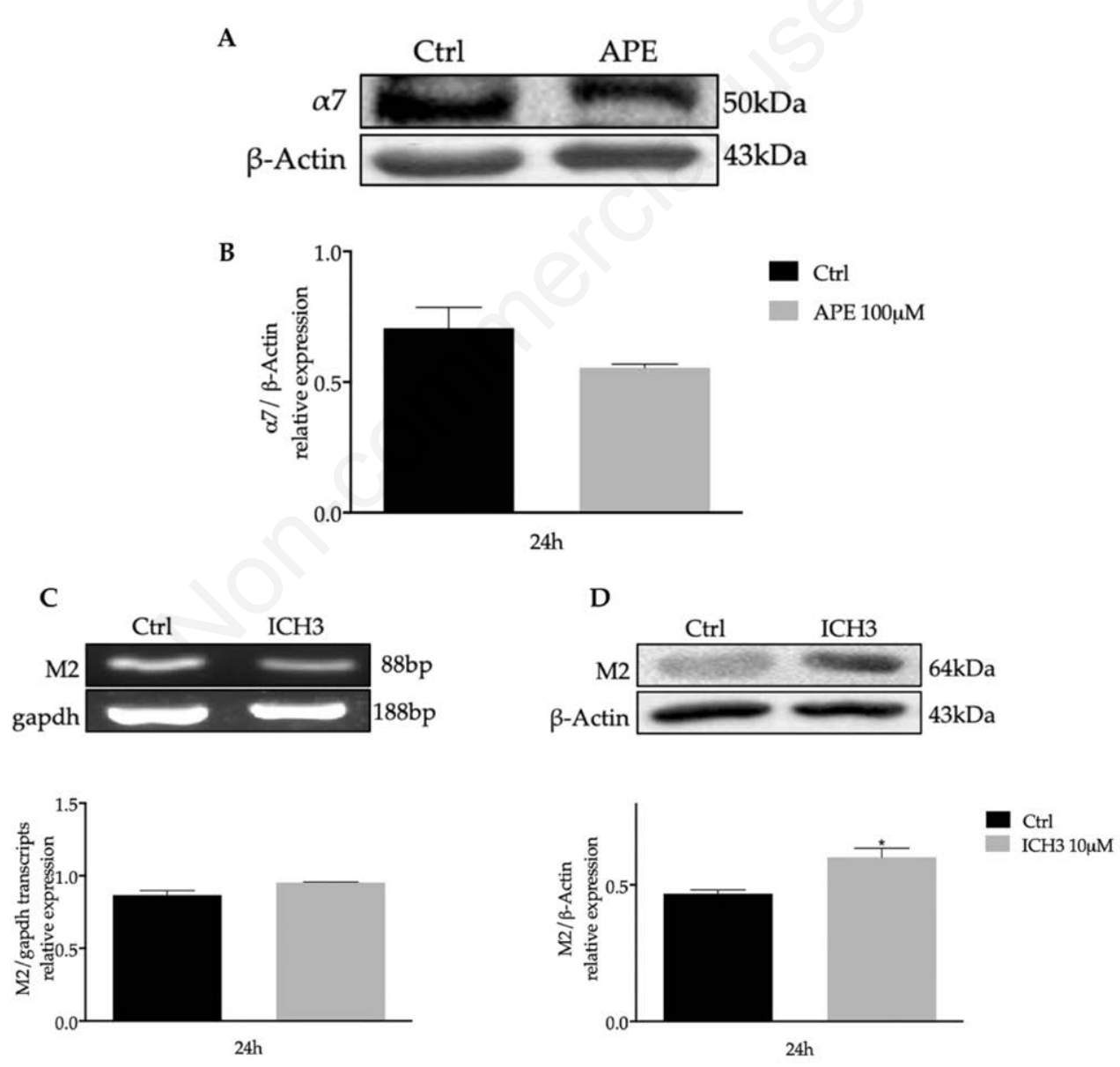

Figure 5. Cross-interaction between nicotinic and muscarinic receptors. A,B) Protein analysis by Western blot of the $\alpha 7$ receptor following treatment with $100 \mu \mathrm{M}$ APE for $24 \mathrm{~h}$ did not show any variation of the protein level; $\beta$-actin was used as the reference protein. C) RT-PCR analysis did not show any modulation of the M2 muscarinic receptor after $\alpha 7$ receptor stimulation; GAPDH was used as housekeeping gene. D) M2 receptor protein expression was significantly upregulated after ICH3 treatment as indicated by western blot analysis; $\beta$-actin was used as the reference protein; the analyses were carried out following the treatment with $10 \mu \mathrm{M}$ ICH3 for $24 \mathrm{~h}$; the data represented are the mean \pm SEM of three independent experiments; ${ }^{*} \mathbf{p}<0.05$. 
nicotinic or M2 muscarinic receptors, respectively.

In conclusion, the results obtained in this study clearly demonstrate the role of ACh and its receptors in the modulation of ASC proliferation and migration. Although more detailed investigations are needed to fully understand how and when the different cholinergic receptors are expressed by ASCs in vivo, our data confirm the additional non-neuronal functions of $\mathrm{ACh}$ and its receptors as reported in different tissues, ${ }^{38,47,48,52,55}$ and indicate that the cholinergic transmission, mediated by $\mathrm{M} 2$ and $\alpha 7$ receptors, may contribute to the modulation of the physiological process of ASCs.

\section{Acknowledgements}

This work was supported by Ateneo Sapienza Funds 2017 (RM11715C7F959CA4) to AMT and "Avvio Giovani" Project 2018 (AR11816435A0F81D) from Ateneo Sapienza to RP. RP was also supported by CIB 2018. AF and AJR are supported by the Hargreaves and Ball Trust, the Academy of Medical Sciences (AMS-SGCL7), and by Seed Corn Funding from the Rosetrees Trust and the Stoneygate Trust (M746).

\section{References}

1. Frith J, Genever P. Transcriptional control of mesenchymal stem cell differentiation. Transfus Med Hemother 2008;35: 216-27.

2. Bobis S, Jarocha D, Majka M. Mesenchymal stem cells: Characteristics and clinical applications. Folia Histochem Cytobiol 2006;44:215-30.

3. Rodrigues M, Griffith LG, Wells A. Growth factor regulation of proliferation and survival of multipotential stromal cells. Stem Cell Res Ther 2010;1:1-12.

4. Nakagami H, Morishita R, Maeda K, Kikuchi Y, Ogihara T, Kaneda Y. Adipose tissue-derived stromal cells as a novel option for regenerative cell therapy. J Atheroscler Thromb 2006; $13: 77-81$

5. Castro-Manrreza ME, Montesinos JJ. Immunoregulation by mesenchymal stem cells: Biological aspects and clinical applications. J Immunol Res 2015;2015:1-20.

6. Mishra VK, Shih H-H, Parveen F, Lenzen D, Ito E, Chan T-F, et al. Identifying the therapeutic significance of mesenchymal stem cells. Cells 2020;9:1145.

7. Jiang W, Xu J. Immune modulation by mesenchymal stem cells. Cell Prolif 2020;53:1-16.

8. Caddick J, Kingham PJ, Gardiner NJ, Wiberg M TG. Phenotypic and functional characteristics of mesenchymal stem cells differentiated along a schwann cell lineage. Glia 2006;54:840-9.

9. Gimble JM, Katz AJ, Bunnell BA. Adipose-derived stem cells for regenerative medicine. Circ Res 2007;100:1249-60.

10. Strem MS, Hicok KC, Zhu M, Wulur I, Z Alfonso, Schreiber $\mathrm{RE}$, et al. Multipotential differentiation of adipose tissuederived stem cells. Keio J Med 2005;54:132-41.

11. Ilic D, Polak JM. Stem cells in regenerative medicine: Introduction: Br Med Bull 2011;98:117-26.

12. Mizuno H, Tobita M, Uysal AC. Concise review: Adiposederived stem cells as a novel tool for future regenerative medicine. Stem Cells 2012;804-10.

13. Qomi RT, Sheykhhasan M. Adipose-derived stromal cell in regenerative medicine: A review. World J Stem Cells 2017;9:107-17.

14. Zuk PA, Zhu M, Ashjian P, De Ugarte DA, Huang JI, Mizuno
$\mathrm{H}$, et al. Human adipose tissue is a source of multipotent stem cells. Mol Biol Cell 2002;13:4279-95.

15. Bunnell BA, Flaat M, Gagliardi C, Patel B, Ripoll C. Adiposederived stem cells: Isolation, expansion and differentiation. Methods 2008;45:1-11.

16. Locke M, Windsor J, Dunbar PR. Human adipose-derived stem cells: isolation, characterization and applications in surgery. ANZ J Surg 2009;79:235-44.

17. Mazini L, Rochette L, Amine M, Malka G. Regenerative capacity of adipose derived stem cells (ADSCs), comparison with mesenchymal stem cells (MSCs). Int J Mol Sci 2019;20:2523.

18. Kingham PJ, Kalbermatten DF, Mahay D, Armstrong SJ, Wiberg M, Terenghi G. Adipose-derived stem cells differentiate into a Schwann cell phenotype and promote neurite outgrowth in vitro. Exp Neurol 2007;207:267-74.

19. Zhao L, Johnson T, Liu D. Therapeutic angiogenesis of adipose-derived stem cells for ischemic diseases. Stem Cell Res Ther 2017;8:1-9.

20. Han C, Zhang L, Song L, Liu Y, Zou W, Piao H, et al. Human adipose-derived mesenchymal stem cells: A better cell source for nervous system regeneration. Chin Med J (Engl) 2014; 127:329-37.

21. Jiang L, Zhu J-K, Liu X-L, Xiang P, Hu J, Yu W-H. Differentiation of rat adipose tissue-derived stem cells into Schwann-like cells in vitro. Neuroreport 2008;19:1015-9.

22. Timper K, Seboek D, Eberhardt M, Linscheid P, Christ-Crain M, Keller U, et al. Human adipose tissue-derived mesenchymal stem cells differentiate into insulin, somatostatin, and glucagon expressing cells. Biochem Biophys Res Commun 2006;341:1135-40.

23. Kingham PJ, Reid AJ, Wiberg M. Adipose-derived stem cells for nerve repair: Hype or reality? Cells Tissues Organs 2014;200:23-30.

24. Vindigni V, Giatsidis G, Reho F, Dalla Venezia E, Mammana M, Franco B. Adipose derived stem cells: current state of the art and prospective role in regenerative medicine and tissue engineering. In: J.A. Andrade, editor. Regenerative Medicine and Tissue Engineering. InTech Open; 2013. doi: $10.5772 / 55924$.

25. Frese L, Dijkman PE, Hoerstrup SP. Adipose tissue-derived stem cells in regenerative medicine. Transfus Med Hemotherapy 2016;43:268-74.

26. Bajek A, Gurtowska N, Olkowska J, Kazmierski L, Maj M, Drewa T. Adipose-derived stem cells as a tool in cell-based therapies. Arch Immunol Ther Exp (Warsz) 2016;64:443-54.

27. Loreti S, Vilaró MT, Visentin S, Rees H, Levey AI, Tata AM. Rat Schwann cells express M1-M4 muscarinic receptor subtypes. J Neurosci Res 2006;84:97-105.

28. Uggenti C, De Stefano ME, Costantino M, Loreti S, Pisano A, Avallone B, et al. M2 muscarinic receptor activation regulates schwann cell differentiation and myelin organization. Dev Neurobiol 2014;74:676-91.

29. Di Bari M, Di Pinto G, Reale M, Mengod G, Tata AM. Cholinergic system and neuroinflammation: implication in multiple sclerosis. Cent Nerv Syst Agents Med Chem 2016;17:1-7.

30. Reale M, Di Bari M, Di Nicola M, D'Angelo C, De Angelis F, Velluto L, et al. Nicotinic receptor activation negatively modulates pro-inflammatory cytokine production in multiple sclerosis patients. Int Immunopharmacol 2015;29:152-7.

31. Zhang H, Guo D, Wang L, Zhao Y, Cheng Y, Qiao Z. Effect of nicotine on Oct-4 and Rex-1 expression of mouse embryonic stem cells. Reprod Toxicol 2005;19:473-8.

32. Piovesana R, Melfi S, Fiore M, Magnaghi V, Tata AM. M2 
muscarinic receptor activation inhibits cell proliferation and migration of rat adipose-mesenchymal stem cells. J Cell Physiol 2018;233:5348-60.

33. Hoogduijn MJ, Cheng A, Genever PG. Functional nicotinic and muscarinic receptors on mesenchymal stem cells. Stem Cells Dev 2009;18:103-12.

34. Schraufstatter IU, DiScipio RG, Khaldoyanidi SK. Alpha 7 subunit of $\mathrm{nAChR}$ regulates migration of human mesenchymal stem cells. J Stem Cells 2009;4:203-15.

35. De Jaco A, Bernardini L, Rosati J, Tata AM. Alpha-7 Nicotinic receptors in nervous system disorders: from function to therapeutic perspectives. Cent Nerv Syst Agents Med Chem 2016;17:1-9.

36. Wang H, Yu M, Ochani M, Amella CA. Nicotinic acetylcholine receptor a 7 subunit is an essential regulator of inflammation. Nature 2003;421:384-8.

37. De Jonge WJ, Ulloa L. The alpha7 nicotinic acetylcholine receptor as a pharmacological target for inflammation. Br J Pharmacol 2007;151:915-29.

38. Fujii T, Takada-takatori Y, Kawashima K. Basic and clinical aspects of non-neuronal acetylcholine: expression of an independent, non-neuronal cholinergic system in lymphocytes and its clinical significance in immunotherapy. J Pharmacol Sci 2008;106:186-92.

39. Gallowitsch-Puerta M, Tracey KJ. Immunologic role of the cholinergic anti-inflammatory pathway and the nicotinic acetylcholine $\alpha 7$ receptor. Ann N Y Acad Sci 2005;1062:20919.

40. Piovesana R, Faroni A, Magnaghi V, Reid AJ, Tata AM. M2 receptors activation modulates cell growth, migration and differentiation of rat Schwann-like adipose-derived stem cells. Cell Death Discov 2019;5:92.

41. Dallanoce C, Magrone P, Matera C, Frigerio F, Grazioso G, De Amici $\mathrm{M}$, et al. Design, synthesis, and pharmacological characterization of novel spirocyclic quinuclidinyl- $\Delta 2$-isoxazoline derivatives as potent and selective agonists of $\alpha 7$ nicotinic acetylcholine receptors. Chem Med Chem 2011;6:889-903.

42. Di Cesare Mannelli L, Pacini A, Matera C, Zanardelli M, Mello T, De Amici M, et al. Involvement of $\alpha 7 \mathrm{nAChR}$ subtype in rat oxaliplatin-induced neuropathy: Effects of selective activation. Neuropharmacology 2014;79:37-48.

43. Scabia G, Cancello R, Dallanoce C, Berger S, Matera C, Dattilo A, et al. ICH3, a selective alpha7 nicotinic acetylcholine receptor agonist, modulates adipocyte inflammation associated with obesity. J Endocrinol Invest 2020;43:983-93.

44. Matera C, Dondio G, Braida D, Ponzoni L, De Amici M, Sala $\mathrm{M}$, et al. In vivo and in vitro ADMET profiling and in vivo pharmacodynamic investigations of a selective $\alpha 7$ nicotinic acetylcholine receptor agonist with a spirocyclic $\Delta 2$-isoxazoline molecular skeleton. Eur J Pharmacol 2018;820:265-73.

45. Piovesana R, Faroni A, Taggi M, Matera A, Soligo M, Canipari $\mathrm{R}$, et al. Muscarinic receptors modulate Nerve Growth Factor production in rat Schwann-like adipose-derived stem cells and in Schwann cells. Sci Rep 2020;10:7159.

46. Faroni A, Mobasseri SA, Kingham PJ, Reid AJ. Peripheral nerve regeneration: Experimental strategies and future perspectives. Adv Drug Deliv Rev 2015;82:160-7.

47. Kirkpatrick CJ, Grando SA, Wessler I, Kawashima K, Meurs $\mathrm{H}$. The non-neuronal cholinergic system: Basic science, therapeutic implications and new perspectives. Life Sci 2012;91:969-72.

48. Wessler IK, Kirkpatrick CJ. Non-neuronal acetylcholine involved in reproduction in mammals and honeybees. $\mathrm{J}$ Neurochem 2017;142:144-50.

49. Eglen RM. Muscarinic receptor subtypes in neuronal and nonneuronal cholinergic function. Auton Autacoid Pharmacol 2006;26:219-33.

50. Wessler I, Kirkpatrick CJ. Acetylcholine beyond neurons: The non-neuronal cholinergic system in humans. Br J Pharmacol 2008;154:1558-71.

51. Grando SA, Kawashima K, Kirkpatrick CJ, Kummer W, Wessler I. Recent progress in revealing the biological and medical significance of the non-neuronal cholinergic system. Int Immunopharmacol 2015;29:1-7.

52. Wessler I, Kilbinger H, Bittinger F, Unger R, Kirkpatrick CJ. The non-neuronal cholinergic system in humans: Expression, function and pathophysiology. Life Sci 2003;72:2055-61.

53. El-Habta R, Kingham PJ, Backman LJ. Adipose stem cells enhance myoblast proliferation via acetylcholine and extracellular signal-regulated kinase $1 / 2$ signaling. Muscle Nerve 2018;57:305-11.

54. Liu M, Lei H, Dong P, Fu X, Yang Z, Yang Y, et al. Adiposederived mesenchymal stem cells from the elderly exhibit decreased migration and differentiation abilities with senescent properties. Cell Transplant 2017;26:1505-19.

55. Wessler I, Kirkpatrick CJ, Racké K. The cholinergic "pitfall”: Acetylcholine, a universal cell molecule in biological systems, including humans. Clin Exp Pharmacol Physiol 1999;26:198-

Received for publication: 13 July 2020. Accepted for publication: 25 September 2020.

This work is licensed under a Creative Commons Attribution-NonCommercial 4.0 International License (CC BY-NC 4.0).

CCopyright: the Author(s), 2020

Licensee PAGEPress, Italy

European Journal of Histochemistry 2020; 64(s2):3159

doi:10.4081/ejh.2020.3159 